\title{
Thin-Film Calorimetry: Analytical Tool for In-Situ Characterization of Lithium Ion Batteries
}

\author{
Hendrik Wulfmeier, ${ }^{\mathrm{a}, *, \mathrm{z}}$ Daniel Albrecht, ${ }^{\mathrm{a}}$ Julian Fischer, ${ }^{\mathrm{b}}$ Svetlozar Ivanov, ${ }^{\mathrm{c}, *}$ \\ Andreas Bund, ${ }^{\mathrm{c}, *}$ Sven Ulrich, ${ }^{\mathrm{b}}$ and Holger Fritze ${ }^{\mathrm{a}}$
}

\author{
${ }^{a}$ Clausthal University of Technology, Institute of Energy Research and Physical Technologies and Energy Research \\ Centre of Niedersachsen, D-38640 Goslar, Germany \\ ${ }^{b}$ Karlsruhe Institute of Technology, Institute of Applied Materials, D-76344 Eggenstein-Leopoldshafen, Germany \\ ${ }^{c}$ Ilmenau University of Technology, Department of Electrochemistry and Electroplating, D-98693 Ilmenau, Germany
}

\begin{abstract}
Thin-Film Calorimetry (TFC) as presented in this work is a novel analytical tool to determine phase transformation temperatures and enthalpies of thin films and thin-film sequences. The key component is a high-temperature stable piezoelectric langasite $\left(\mathrm{La}_{3} \mathrm{Ga}_{5} \mathrm{SiO}_{14}\right)$ resonator serving as a highly sensitive planar temperature sensor. Deviations in its frequency are related to temperature fluctuations caused by phase transformations and used to calculate the related enthalpies. Temperature ramps from room temperature up to $1000^{\circ} \mathrm{C}$ are applied to perform calorimetric thin-film investigations. Thereby, the atmosphere can be controlled. To the best of our knowledge, the presented TFC is the only existing technique combining the aspects "thin films" and "high-temperature calorimetry." The first part of this article describes the newly developed TFC system. The second part presents TFC investigations on lithium manganese oxide (LMO) thin films. Measurements are carried out in ambient air and in $0.5 \% \mathrm{H}_{2} / \mathrm{Ar}$. In air three phase transformations appear (at 330, 410 and $600^{\circ} \mathrm{C}$ ) while in $0.5 \% \mathrm{H}_{2} / \mathrm{Ar}$ four phase transformations are observed (at $389,471,730$ and $758^{\circ} \mathrm{C}$ ). Their progression and related enthalpies are discussed. To determine the associated crystallographic phases, X-ray diffraction and Raman spectroscopy are performed.

(C) The Author(s) 2015. Published by ECS. This is an open access article distributed under the terms of the Creative Commons Attribution Non-Commercial No Derivatives 4.0 License (CC BY-NC-ND, http://creativecommons.org/licenses/by-nc-nd/4.0/), which permits non-commercial reuse, distribution, and reproduction in any medium, provided the original work is not changed in any way and is properly cited. For permission for commercial reuse, please email: oa@electrochem.org. [DOI: 10.1149/2.0741504jes] All rights reserved.
\end{abstract}

Manuscript submitted November 5, 2014; revised manuscript received January 12, 2015. Published February 6, 2015. This was Paper 740 presented at the Como, Italy, Meeting of the IMLB, June 10-14, 2014.

\section{Motivation}

In the last decades, the research interest in thin-film batteries arises mainly because of two reasons:

1) Model systems based on thin-film battery layers and layer sequences - Lab-scaled systems and layer sequences are used to investigate interface and degradation phenomena during charging and discharging.

2) Thin-film electrodes and all-solid-state electrochemical cellsThin films are used in miniaturized battery cells ${ }^{1,2}$ in combination with liquid or solid electrolytes. The latter so called all-solidstate electrochemical cells are of interest for e.g. medical and bio technologies where toxic and liquid electrolytes should be avoided. ${ }^{3}$ Another application example are batteries for harsh environments such as elevated temperatures.

Even for electrochemical cells operating at low temperatures it is necessary to evaluate the thermodynamic materials data in a wider range, preferentially up to the synthesis temperature which can often be close to $1000^{\circ} \mathrm{C} .^{4,5}$ For example, the optimum synthesis temperature for $\mathrm{LiFePO}_{4}$ is found to be between 700 and $800^{\circ} \mathrm{C}$. ${ }^{6}$ Preparation routes for $\mathrm{Li}_{2} \mathrm{MnO}_{3}$ and $\mathrm{LiNi}_{0.5} \mathrm{Mn}_{0.5} \mathrm{O}_{2}$ include synthesis temperatures of $800^{7}$ and $1000^{\circ} \mathrm{C},{ }^{8}$ respectively. The anode material molybdenum disulfide shows a strong dependence of its morphology on calcination steps after synthesis. ${ }^{9,10}$ In all-solid-state batteries sometimes more than one layer has to be annealed at several hundred degrees Celsius to achieve the desired crystallographic phases.

One key issue for the development of thin films and all-solid-state thin-film electrochemical cells is the precise knowledge of the phases and their thermodynamic properties. Thereby, one has to consider that:

1) Thin films behave, in general, differently compared to bulk materials. The latter are, for example, less affected by surface reactions.
2) Materials properties reported for thin films often differ from bulk properties. ${ }^{11}$ The statement concerns e.g. the melting point reduction, ${ }^{12}$ higher resistivity ${ }^{13}$ or a change in the mechanical properties, such as residual stresses and elastic constants. ${ }^{14}$

Accessing these thermodynamic data is a major challenge. Standard and well-known calorimetric techniques (e.g. Differential Scanning Calorimetry, DSC) are predominantly suited for bulk samples. The mass of thin-film samples is comparably low and often insufficient to detect phase transformations. Consequently, there is a general demand for calorimetric techniques to investigate thin films. Currently available systems show some restrictions. Each of it has its special operation range, although none of it covers very high temperatures.

\section{State of the Art}

The development of calorimeters for the investigation of thin films and the adaption of classic calorimetric methods for this type of measurement is the topic of numerous publications. ${ }^{15-18}$

Current calorimetric systems suited for thin films.- Currently used methods in the field of calorimetry on thin films are mainly based on three methods: ${ }^{19}$

(1) Si- and Si-N-membrane based concepts - The so called Chip or Integrated Circuit Calorimeters (IC calorimeter) exhibit a very high sensitivity, which is only achievable by the use of extremely thin monocrystalline silicon membranes or of dielectric Si-N membranes. ${ }^{20,21}$ These membranes are highly fragile and do not tolerate mechanical stress at elevated temperatures which limits, in general, the maximum operation temperature to about $500^{\circ} \mathrm{C} .{ }^{20}$ Complex models are necessary to consider the measured effects in the correct manner. Often, the measurement accuracy is determined by these models. ${ }^{22}$ The chip devices are mostly single-use objects since a mechanical or chemical detachment of the active layer(s) destroys commonly the membrane. Therefore, the main application area of these systems is the investigation of liquids and gaseous samples..$^{23,24}$ 
(2) Adaptions of conventional DSC systems - In order to investigate optically and thermally induced solid-state reactions photocalorimetry can be applied. ${ }^{25}$ Here, the energy supply is realized by light (UV or VIS). The optical penetration depth of the used radiation defines the maximum sample volume explored and limits this method to effects occurring in the vicinity of the surface. The Tian-Calvet microcalorimetry is particularly applied for adsorption and immersion calorimetry. The application temperature ranges up to about $300^{\circ} \mathrm{C} .{ }^{26}$ Another direct calorimetric approach is the use of freestanding thin films. ${ }^{27}$ The method requires the detachment of the film from the substrate where the films are originally deposited. This process is quite complex and cannot be used for many materials. Alternatively, sequential multilayer stacks deposited on thin substrates are applied. They increase the mass ratio $m_{\text {film }}: m_{\text {substrate }}$ while still behaving like single thin-film layers. ${ }^{28}$ However, both methods suffer from the low sample masses which might result in insufficient measurement signals. Temperature-modulated DSC systems (TM-DSC) lead to increased instantaneous heat output and, thereby, higher sensitivities for polymers. ${ }^{29}$

(3) Quartz resonators - The investigation of gas-surface interactions using the combination of an IC calorimeter and a quartz microbalance is presented in Ref. 30. Other quartz resonator based approaches are described in Refs. 31 and 32. In contrast to the work presented here, these measurements are carried out at constant temperatures, however always remaining below $100^{\circ} \mathrm{C}$. One of the first approaches using the temperature dependent resonance frequency is presented in Ref. 33. There, the combustion heat of flammable gases is measured in order to determine their concentration. A comparable approach is applied in Ref. 34. Here, two quartz resonators are used for the detection of $\mathrm{H}_{2}$.

In summary, most of these methods suffer from a limited maximum operating temperature and are not suitable for the needs described in this work. The only approach capable to work above $500^{\circ} \mathrm{C}$, is the use of detached layers which cannot be applied for many materials of interest. DSC based methods are problematic as they exhibit, in general, a quite unfavorable mass relation of film and substrate.

The most promising approach for calorimetry on thin films seems to be the use of high-temperature stable piezoelectric crystals as calorimetric sensor. In general, quartz single crystals are only applicable up to $573^{\circ} \mathrm{C}$ (solid-solid phase transformation from $\alpha$ - to $\beta$-quartz). Moreover, the range of application is already limited to about $350^{\circ} \mathrm{C}$ since damping strongly increases above this temperature which limits the accuracy in determination of the resonance frequency. ${ }^{35}$ Therefore, any use of this approach for temperature ranges above $350^{\circ} \mathrm{C}$ requires high-temperature stable piezoelectric resonator materials.

Langasite as a high-temperature stable sensor material.- The limits of quartz are already described in the previous section. Other piezoelectric materials such as congruent $\mathrm{LiNbO}_{3}$ suffer from strong degradation starting already at about $300^{\circ} \mathrm{C} .{ }^{36}$ Stoichiometric $\mathrm{LiNbO}_{3}$ is predicted to be more stable. The same is valid for e.g. $\mathrm{GaPO}_{4}$ (maximum temperature $970^{\circ} \mathrm{C}$ ) ${ }^{35}$ However, crystal growth of these latter two materials is very challenging. Therefore, their abundance is limited. Figure 1 shows the resonance frequency dependence on temperature and the ultimate application limits of different piezoelectric single crystals.

In order to enable operation temperatures of at least $1000^{\circ} \mathrm{C}$ langasite single crystals $\left(\mathrm{La}_{3} \mathrm{Ga}_{5} \mathrm{SiO}_{14}, \mathrm{LGS}\right)$ are chosen. LGS resonators can be excited piezoelectrically to bulk acoustic shear waves up to their melting point at $1470^{\circ} \mathrm{C}$. Even at about $1100^{\circ} \mathrm{C}$ the damping of $5 \mathrm{MHz}$ resonators used for this work is sufficiently low to determine the resonance frequency with sufficient accuracy. ${ }^{35}$ Another beneficial characteristic of LGS is its stability even at low oxygen partial pressures $\left(p_{\mathrm{O}_{2}}\right)$. At $600^{\circ} \mathrm{C}$ LGS is stable down to $p_{\mathrm{O}_{2}}=10^{-21}$ bar. $^{35,37,38}$ Therefore, a LGS resonator based TFC can be applied in reducing atmospheres without degradation of the sensor element.

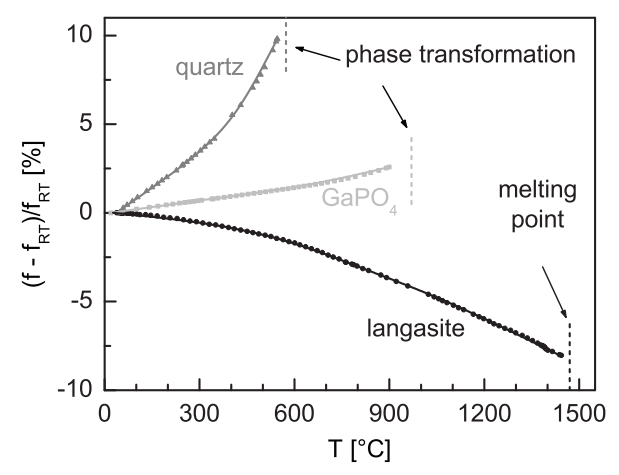

Figure 1. Temperature dependent resonance frequency $f$ of piezoelectric crystals and related operation temperature limits. $f_{R T}$ is the resonance frequency at room temperature. ${ }^{35}$

\section{Thin-Film Calorimetry based on Planar Temperature Sensors}

Working principle of the newly developed approach.- Langasite resonators serve as highly sensitive temperature sensors taking advantage of their temperature dependent resonance frequency. Depending on their orientation, they exhibit a temperature dependent frequency of several hundred Hertz per Kelvin (e.g. $-100 \mathrm{~Hz} / \mathrm{K}$ at $200^{\circ} \mathrm{C}$ ). The (absolute) value increases with temperature. Most important, the temperature dependent frequency of a pristine resonator is strongly monotonous in the measurement range from room temperature (RT) up to its melting point, not indicating any irregularities. ${ }^{39}$ Further, highly conductive thin-film electrodes which do not show phase transformations are required. Consequently, platinum coated LGS resonators can be used as a sensor platform to detect temperature fluctuations caused by additional thin films, i.e. battery materials in our study. They form the key component of the TFC system. ${ }^{39,40}$

The resonators are coated with the film of interest. As long as there are no reactions or phase transformations, the temperature of the resonator follows closely that of the furnace and a continuously decreasing frequency is observed (see Figure 1). Disturbances due to e.g. phase transformations of the films influence the temperature and, thereby, the resonance frequency. Two cases, i.e. endothermic and exothermic processes (see Figure 2), can be distinguished: Endothermic reactions go along with a reduced temperature increase in the film and resonator and, consequently, with reduced frequency decrease. During exothermic phase transformations, heat is generated and the resonance frequency decreases more rapidly. ${ }^{39}$

These frequency fluctuations are determined using a network analyzer ${ }^{41}$ and are converted to enthalpies as described below.

Data evaluation.- An undisturbed LGS resonator exhibits approximately a parabolic temperature dependence of its resonance frequency. Deviations due to phase transformations are regarded as a disturbance of the overall system. Figure 3 shows an idealized frequency progression for an exothermic phase transformation. The measurement signal is fitted in a range of about $50 \mathrm{~K}$ directly prior to the phase transformation by a second order polynomial function. This parabolic fit is extrapolated beyond the phase transformation (dashed line in Figure 3) and regarded as the reference frequency of the undisturbed system. The temperature $T_{P T}$, at which the phase transformation starts, is given by a starting deviation of the measurement data from the extrapolated fit curve. To determine the frequency shift $\Delta f_{P T}$, the relaxation of the system resonator and film after accomplishing the phase transformation is investigated. In this range a simple linear fit (solid line in Figure 3 ) can be applied as the fit covers a range of a few Kelvin, only. Multiplication of the frequency shift $\Delta f_{P T}$ with the temperature coefficient of the resonance frequency $c_{T}$ gives the characteristic change in temperature $\Delta T_{P T}$ that is associated with the observed phase transformation:

$$
\Delta T_{P T}=c_{T} \Delta f_{P T}=c_{T}\left[f_{\text {linear }}\left(T_{P T}\right)-f_{\text {parabolic }}\left(T_{P T}\right)\right]
$$



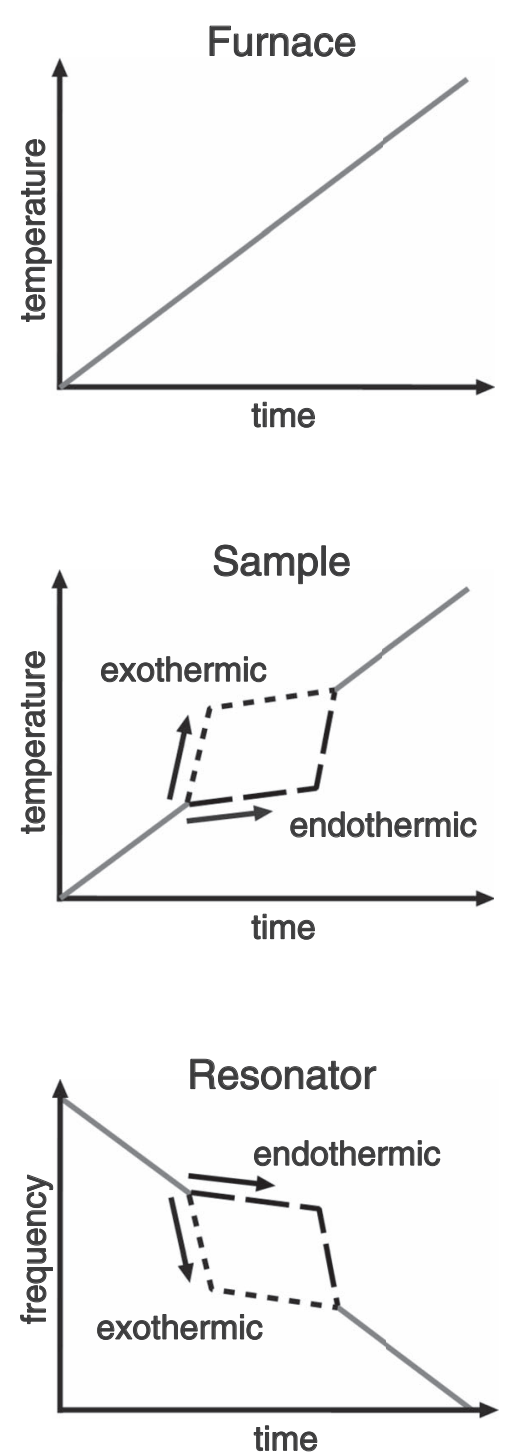

Figure 2. Continuous heating of the furnace (top), impact of a phase transformation on the sample temperature (middle) and the resonance frequency (bottom). The deviations caused by an exothermic or endothermic phase transformation are indicated by dotted and dashed lines, respectively.

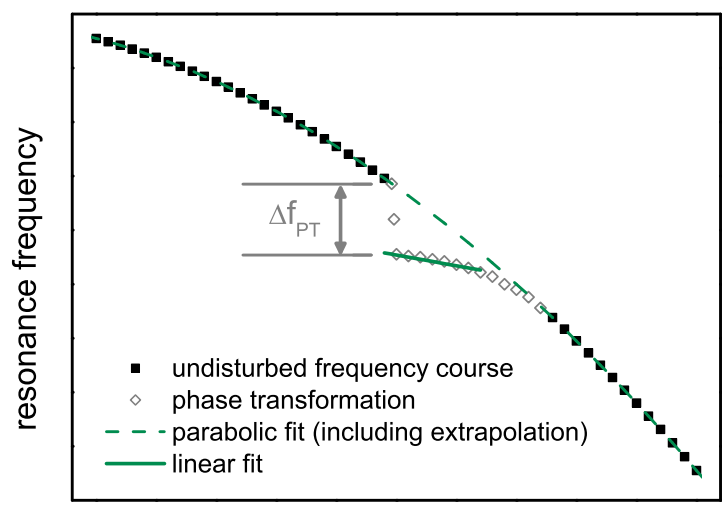

temperature

Figure 3. Idealized frequency progression related to an exothermic phase transformation. The extrapolated parabolic and linear fits are shown by dashed and solid lines, respectively.
Multiplication of $\Delta T_{P T}$ with the heat capacity of the resonator $q_{r e s}$ results in the amount of heat $Q_{P T}$ that is generated (exothermic process) or consumed (endothermic process) by the film:

$$
Q_{P T}=\Delta T_{P T} q_{\text {res }}
$$

Here, $q_{\text {Res }}$ is calculated as the product of specific heat capacities $c_{p, i}$ and masses $m_{i}$, summed up over the components of the calorimetric sensor ( $i=$ LGS resonator, Pt electrodes, film of interest):

$$
q_{\text {res }}=\Sigma_{i} m_{i} c_{p, i}=m_{L G S} c_{p, L G S}+m_{P t} c_{p, P t}+m_{\text {film }} c_{p, \text { film }}
$$

Two points have to be considered: First, the specific heat capacity of newly synthesized materials is, in general, unknown. In this case, the last term cannot be calculated. It could be estimated, if sufficient information on comparable materials is known. However, this uncertainty in calculation is only a minor drawback. Due to previous tests with well-known reference samples of tin and aluminum, the error at omitting the last term is only about $1 \%$ of the total accuracy. ${ }^{39}$ This deviation is still in the range of the accuracy of established calorimetric techniques. ${ }^{42}$ Second, the mass of the LGS resonator is reduced to the piezoelectrically excited volume. The approach is justified if the heat fluxes inside the resonator are taken into account. ${ }^{39}$

Finally, the division of $Q_{P T}$ by the film mass $m_{f i m}$ results in the enthalpy $\Delta H$ :

$$
\Delta H=-Q_{P T} / m_{f i l m}
$$

A more detailed description of the measurement system and of the data evaluation is given in Refs. 39 and 40.

Experimental setup.- Piezoelectric langasite resonators (Y-cut, diameter: $10 \mathrm{~mm}$, thickness: $\sim 260 \mu \mathrm{m}$, resonance frequency at RT: $\sim 5.2 \mathrm{MHz}$, thickness shear mode) are coated with keyhole shaped platinum or platinum/rhodium electrodes (thickness: 200-300 nm, diameter: $5 \mathrm{~mm}$ ) and the film of interest as shown in Figure 4. In order to get very smooth electrode surfaces, they are applied via pulsed laser deposition (PLD). The typical roughness is in the range of 5 to $15 \mathrm{~nm}$. Thin titanium layers $(\sim 10 \mathrm{~nm})$ are applied on the LGS substrates prior to platinum deposition to enhance the adhesion.

Figure 5 shows a photograph of the TFC setup as well as a scheme of the cross-section. The resonator and connecting platinum wires are clamped inside the sample holder (fused silica glass) only at four small support points to reduce mechanical damping and thermal coupling of the system resonator/film and the sample holder.

The approximate temperature of the system is measured by a thermocouple type $S$ in close vicinity to the resonator (1-2 mm). The thermocouple and the resonator electrodes are connected to a digital voltmeter (Keithley DVM 2000, USA) and a high-speed network analyzer (Agilent E5100A, USA), respectively.

The resonator support is installed in a single-end closed quartz glass tube. The sample chamber can be evacuated or filled with a gas of choice. A constant gas flow is used during heating/cooling of the TFC system which is mounted vertically inside a tube furnace (up to $1100^{\circ} \mathrm{C}$, Linn High Therm FRH-42/100/1100, Germany).

The TFC module is transferable into a glove box. There, it can be loaded with resonators already coated with the film of interest. The approach enables measurements on atmospheric sensitive materials.

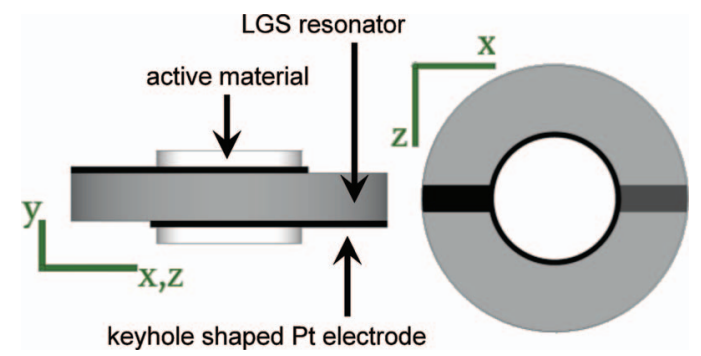

Figure 4. Scheme of a coated LGS resonator. 

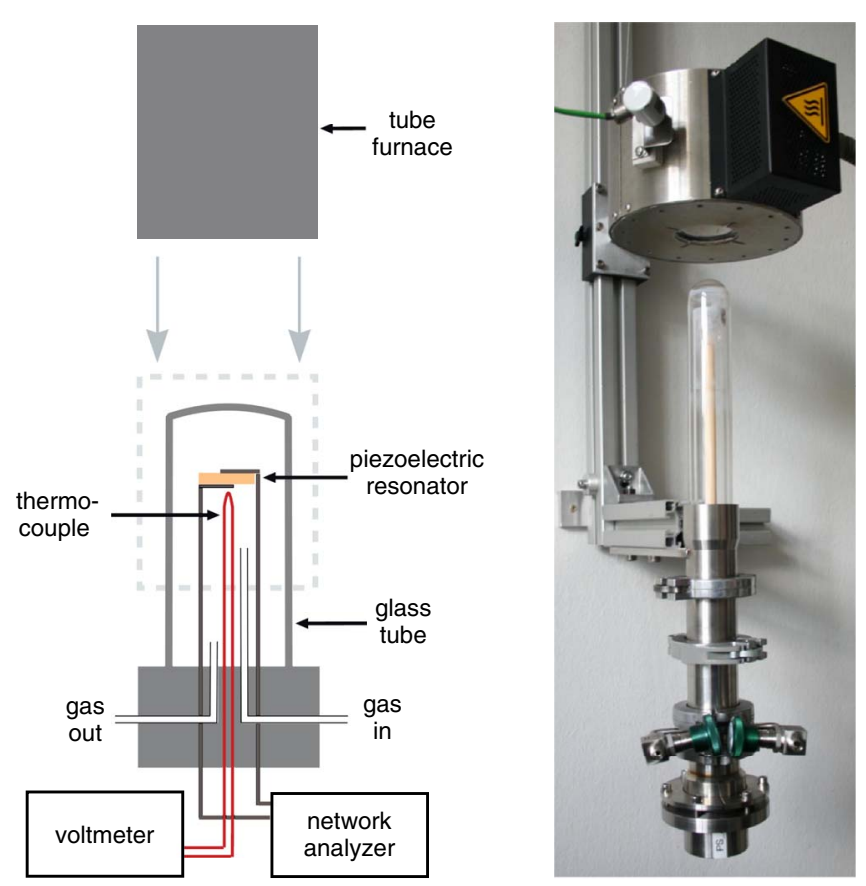

Figure 5. Thin-Film Calorimeter (TFC) based on planar temperature sensors. Scheme (left) and TFC setup with vertically moveable tube furnace (right).

Measurement procedure.- Resonance spectra of the LGS devices are continuously acquired in the vicinity of the resonance frequency and converted to conductance spectra. The maximum of their real part is determined by fitting a Lorentzian function and regarded as resonance frequency. ${ }^{43}$ During the measurement an automatic frequency tracking is realized by a self-written software. After a coarse frequency sweep a second run is performed in the close vicinity of the resonance frequency. Thereby, high accuracy in frequency determination is achieved. ${ }^{39}$ The resonance spectra consist commonly of 400 data points measured with a bandwidth of $1 \mathrm{~ms}$ which allows a sample rate of $0.18 \mathrm{~Hz}$. For each spectrum, the resonance frequency is correlated with the temperature.

Resolution.- The damping of the uncoated LGS resonators is considerable low, so that their frequency at $600^{\circ} \mathrm{C}$ or $1000^{\circ} \mathrm{C}$ can be detected with an accuracy of $\pm 2.5 \mathrm{~Hz}$ or $\pm 4 \mathrm{~Hz}$, respectively. ${ }^{35}$

In Ref. 39 the characterization of reference materials (tin and aluminum) demonstrates the successful operation of the TFC system. If a typical heating rate of $1 \mathrm{~K} / \mathrm{min}$ is applied, the measurement setup shows an uncertainty in frequency determination of $\Delta f \leq 6 \mathrm{~Hz}$ for coated resonators. At $200^{\circ} \mathrm{C}$ the LGS resonator exhibits a temperature dependence of $\Delta f / \Delta T \approx-100 \mathrm{~Hz} / \mathrm{K}$. Consequently, the limit for the accuracy in temperature determination is $\Delta T_{\min }=60 \mathrm{mK}$. $\Delta T_{\min }$ has to be taken into account twice as it influences both frequency determinations, $f_{\text {linear }}\left(T_{P T}\right)$ and $f_{\text {parabolic }}\left(T_{P T}\right)$. Considering an effective mass of $12.4 \mathrm{mg}$ for the LGS resonator and a specific heat capacity of $c_{p, L G S}=0.48 \mathrm{~J} /(\mathrm{g} \mathrm{K})$ (taken from Ref. 44), a resonator heat capacity of $q_{\text {res }}=5.9 \mathrm{~J} / \mathrm{K}$ is calculated. Finally, a resolution of $\Delta Q_{P T \text { min }}=2 \Delta T_{\text {min }} q_{\text {res }} \approx 0.7 \mathrm{~mJ}$ results.

The resolution of the enthalpy determination depends on the actual sample mass. For example, a film of $700 \mu \mathrm{g}$ exhibits a resolution of $\Delta(\Delta H) \approx 1 \mathrm{~J} / \mathrm{g}$.

Other calorimetric techniques show higher resolution compared to the TFC. Examples are DSC or IC calorimeters which are faced with one extreme physical situation, i. e. high temperatures or low sample masses. IC calorimeters exhibit a very high resolution of a few $\mu \mathrm{J} .{ }^{45} \mathrm{In}$ Ref. 46 a $0.2 \mathrm{~nJ}$ high-sensitivity IC calorimeter is presented. However, a use above $300^{\circ} \mathrm{C}$ is not reported. DSC systems show sensitivities in the order of several ten $\mu \mathrm{V} \mathrm{mW}^{-1}$, resulting in a resolution of
$1-10 \mu \mathrm{W}^{47}$ Adapted systems for thin-films can reach a minimum detectable heat of $\sim 50 \mu \mathrm{W}^{26}$

\section{Experimental}

Thin-film deposition. - The resonator blanks used here, are Ycut langasite crystals purchased from Shanghai Institute of Ceramics (Chinese Academy of Sciences, P.R. China). The electrodes are deposited on both sides of the resonators by PLD using a KrF excimer laser (Lambda Physics COMPex 205, Germany). Typical deposition parameters are a pulse length of $25 \mathrm{~ns}$, pulse energies of $200 \mathrm{~mJ}$ (titanium adhesion layer) and $350 \mathrm{~mJ}$ (platinum/rhodium electrodes) and a repetition rate of $10 \mathrm{~Hz}$ and $40 \mathrm{~Hz}$, respectively. Platinum/rhodium is chosen for the electrodes instead of pure platinum as this enhances their stability. The base pressure in the deposition chamber is about $1 \times 10^{-6}$ mbar.

On top of the electroded resonators, the battery material lithium manganese oxide (LMO) is deposited. The films are deposited on both sides of the resonators to minimize mechanical stress during phase transformations in the thin films. A one-sided deposition could result in bending stress and, thereby, unwanted shift of the resonance frequency.

The deposition of LMO is done via r.f. magnetron sputtering (Leybold Heraeus Z550, Germany) using a commercial $\mathrm{LiMn}_{2} \mathrm{O}_{4}$ target (purity: $99.9 \%$, CERAC Inc., USA). The atmosphere and the target power density are pure argon at a pressure of $4 \mathrm{~Pa}$ and $2.2 \mathrm{~W} / \mathrm{cm}^{2}$, respectively. The deposited films are investigated by ICP-OES in combination with Carrier-Gas Heat Extraction and show a stoichiometry of $\mathrm{Li}_{1.064} \mathrm{Mn}_{1.792} \mathrm{O}_{4.144}{ }^{48}$ The diameter of those LMO films is $5 \mathrm{~mm}$. Their thickness is $1 \mu \mathrm{m}$ on each side. The masses of the LMO thin films are $116 \mu \mathrm{g}$ for the TFC characterization in ambient air and $126 \mu \mathrm{g}$ for $0.5 \% \mathrm{H}_{2} / \mathrm{Ar}$.

Several stainless steel substrates (diameter: $12 \mathrm{~mm}$; thickness: $0.5 \mathrm{~mm}$; Hasberg-Schneider GmbH, Germany) are coated in the same series of sputter runs. They serve as reference samples for the investigation of the crystallographic phases. The material 1.4301 (X5CrNi18-10) is chosen as preliminary tests show no signs of oxidation during annealing. Ref. 49 presents XRD spectra of a pristine steel substrate and of one annealed at $800^{\circ} \mathrm{C}$ in ambient air. The annealed sample shows more pronounced reflections than the pristine sample indicating a crystallite growth. However, no additional reflections (e.g. of metal oxides) appear, proving that no material degradation occurs.

Thin-film calorimetry. - The LMO samples are characterized in two different atmospheres, i.e. ambient air and low $p_{O_{2}}$ inert gas atmosphere. For the first, the TFC is not sealed to maintain a constant pressure. For the latter, the TFC is filled with argon (purity: 99.996\%) inside a glove box. During measurement a constant gas flow of $5 \mathrm{sccm} / \mathrm{min}$ of $0.5 \% \mathrm{H}_{2} / \mathrm{Ar}$ (purity: $99.996 \%$ ) is maintained. The reducing gas mixture is chosen to suppress oxidation of the LMO. The TFC measurements are carried out at constant pressure and temperatures up to $774^{\circ} \mathrm{C}$ (ambient air) and $768^{\circ} \mathrm{C}\left(0.5 \% \mathrm{H}_{2} / \mathrm{Ar}\right)$. In both cases a constant heating rate of $1.2 \mathrm{~K} / \mathrm{min}$ is applied.

Further characterizations: Profilometry, microbalance, XRD and Raman spectroscopy.- The film thickness of the electrodes is measured using a profilometer (Ambios XP-2, USA). As the density is known, the electrode masses can be calculated. In this work, the airsensitive LMO film mass is determined inside the TFC system in protecting argon atmosphere, using another benefit of the piezoelectric resonator: The film mass is determined directly by the sensor system with very high precision. Here, the resonator is operated in the microbalance mode by comparing the resonance frequencies prior and after deposition of the film. The mass uptake is calculated via a shift in resonance frequency according to the Sauerbrey equation: ${ }^{35,50}$

$$
m_{\text {film }}=(-A / S) \Delta f_{R}=(-A / S)\left(f_{R, \text { loaded }}-f_{R, \text { unloaded }}\right)
$$

Here, $A$ is the electrode area and $S$ the mass sensitivity of the resonator. The values for the latter are taken from Ref. 35 . 
Structural investigation of the LMO thin films on stainless steel substrates and on the LGS resonators after the TFC measurement are performed by X-ray diffraction (XRD) and Raman spectroscopy. For the investigation at low $p_{O_{2}}$, the reference samples are annealed at 450,550 and $745^{\circ} \mathrm{C}$. To ensure identical process conditions as for the TFC sample, annealing is carried out in the TFC setup using the same parameters. After each annealing step, the reference samples are cooled down with $10 \mathrm{~K} / \mathrm{min}$. As no external cooling is accessible, the cooling rate decreases after passing a temperature of about $200^{\circ} \mathrm{C}$. The reference samples, used for characterization in ambient air, are annealed at 400,500 and $700^{\circ} \mathrm{C}$. After each annealing step, they are quenched to nearly room temperature within 5 minutes.

The XRD patterns are acquired by a Seifert PAD II (USA) diffractometer. The device is operated in the step-scan mode using the BraggBrentano geometry with $\mathrm{Cu}-\mathrm{K}_{\alpha}$ radiation at $\lambda_{X R D}=0.154 \mathrm{~nm}$. The Raman spectra are recorded with a micro-Raman system (Renishaw RM 1000, USA) in combination with an Ar-ion laser (wavelength $\lambda_{\text {Laser }}=514.5 \mathrm{~nm}$, maximum power $23 \mathrm{~mW}$, Soliton, Germany). The laser spot size is $2 \mu \mathrm{m}$. To prevent phase transformations during measurement due to heating by laser light exposure, the maximum output power is reduced to $10 \%$ with a transmission filter. Several Raman spectra at different sample positions are acquired.

\section{Results and Discussion}

Thin-film calorimetry on LMO.- TFC measurements in $0.5 \% \mathrm{H}_{2} / \mathrm{Ar}$ show four phase transformations while in ambient air only three are observed. Independent of the atmosphere, the phase transformations are found during heating only. Upon cooling the frequency shows very smooth and monotone slopes representing undisturbed LGS resonators.

TFC measurements in a $0.5 \% \mathrm{H}_{2} / \mathrm{Ar}$ atmosphere.- LMO heated in a $0.5 \% \mathrm{H}_{2} / \mathrm{Ar}$ atmosphere exhibits phase transformations at (1) $389^{\circ} \mathrm{C}$, (2) $471^{\circ} \mathrm{C}$, (3) $730^{\circ} \mathrm{C}$, and (4) $758^{\circ} \mathrm{C}$. Figure 6 shows the general frequency progression of the resonator during continuous heating. The positions of the four phase transformations are marked. For data analysis enlarged sections, as shown in Figures 7-10, have to be regarded.

Figure 7 shows phase transformation (1) around $389^{\circ} \mathrm{C}$. It starts with a slight frequency deviation from the predicted frequency progression of an undisturbed resonator which is indicated by the extrapolation of the parabolic fit (light gray dashed line; fit range $300 \mathrm{~K}$ to $365 \mathrm{~K}$ ). This onset region is an area of reduced heat consumption which starts slowly about $10 \mathrm{~K}$ prior to the actual phase transformation at $389^{\circ} \mathrm{C}$. At this point a deviation of $\Delta f=+300 \mathrm{~Hz}$ is detected. It is interpreted as an endothermic process which consumes energy to trigger the related crystallization. Subsequently, a frequency drop of $\Delta f=-361 \mathrm{~Hz}$ below the extrapolated parabolic fit of the undisturbed

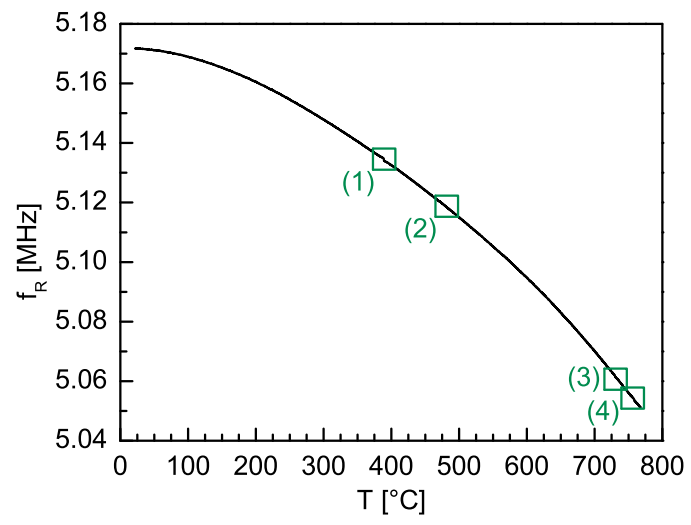

Figure 6. Overview of the TFC diagram for LMO during heating in a $0.5 \% \mathrm{H}_{2} / \mathrm{Ar}$ atmosphere (RT up to $768^{\circ} \mathrm{C}$ ). The positions of the four phase transformations are indicated by squares. Details are shown in Figures 7-10.

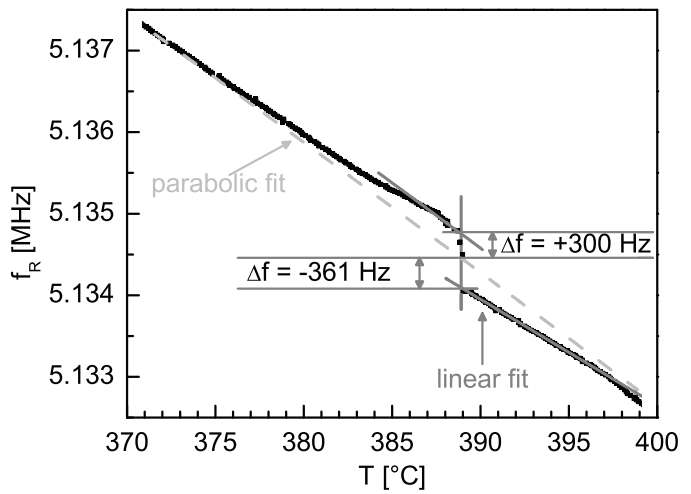

Figure 7. TFC diagram in the vicinity of the 1st phase transformation of LMO in $0.5 \% \mathrm{H}_{2} / \mathrm{Ar}$ around $389^{\circ} \mathrm{C}$.

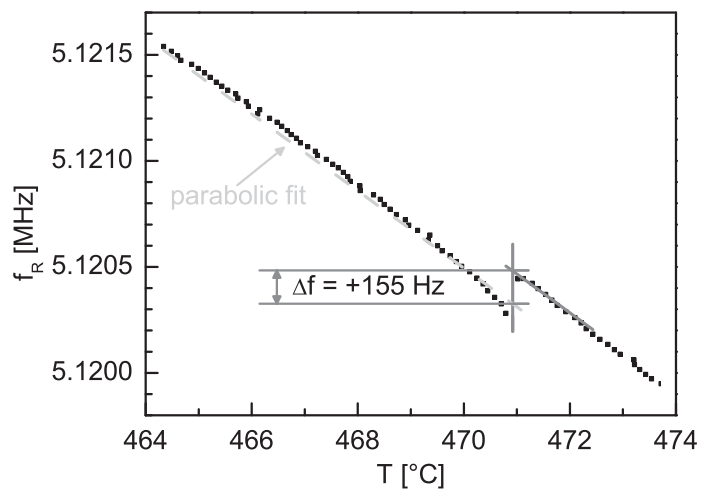

Figure 8. TFC diagram in the vicinity of the 2 nd phase transformation of LMO in $0.5 \% \mathrm{H}_{2} / \mathrm{Ar}$ around $471^{\circ} \mathrm{C}$.

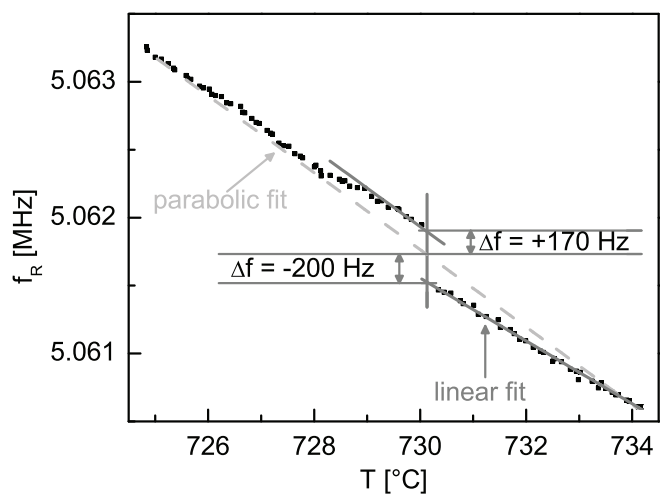

Figure 9. TFC diagram in the vicinity of the 3rd phase transformation of LMO in $0.5 \% \mathrm{H}_{2} / \mathrm{Ar}$ around $730^{\circ} \mathrm{C}$.

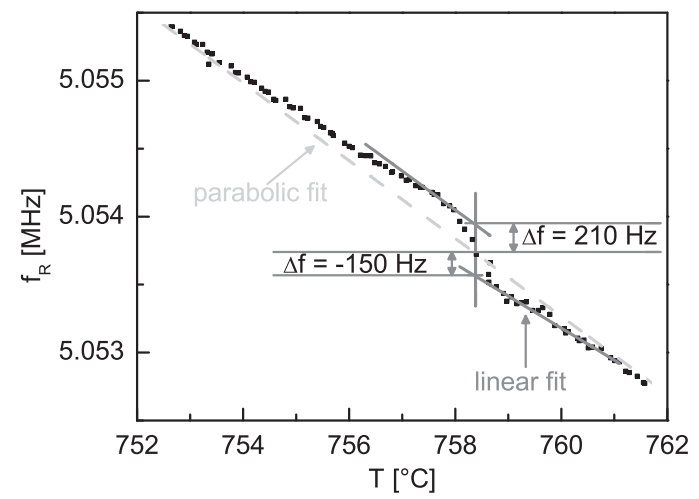

Figure 10. TFC diagram in the vicinity of the 4th phase transformation of LMO in $0.5 \% \mathrm{H}_{2} / \mathrm{Ar}$ around $760^{\circ} \mathrm{C}$. 
Table I. Overview of the phase transformations of LMO. The phase transformation temperatures, the related enthalpies and the associated crystallographic phases are shown.

\begin{tabular}{|c|c|c|c|}
\hline Atmosphere & Phase transformation & $T_{P T}\left[{ }^{\circ} \mathrm{C}\right]$ & $\Delta H[\mathrm{~J} / \mathrm{g}]$ \\
\hline ambient air & $\begin{array}{l}\text { amorphous to } \mathrm{m}-\mathrm{Li}_{2} \mathrm{MnO}_{3} \\
\mathrm{~m}-\mathrm{Li}_{2} \mathrm{MnO}_{3} \text { to } \mathrm{Li}_{1.33} \mathrm{Mn}_{1.67} \mathrm{O}_{4} \\
\mathrm{Li}_{1.33} \mathrm{Mn}_{1.67} \mathrm{O}_{4} \text { to } \mathrm{c}-\mathrm{LiMn}_{2} \mathrm{O}_{4}\end{array}$ & $\begin{array}{l}330 \\
410 \\
600\end{array}$ & $\begin{array}{l}+67.2 /-50.2 \\
+29.3 /-29.3 \\
+20.4 /-26.2\end{array}$ \\
\hline $0.5 \% \mathrm{H}_{2} / \mathrm{Ar}$ & 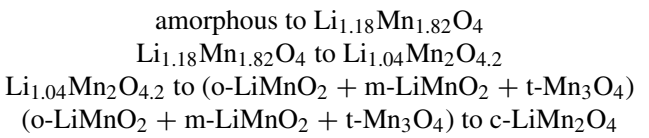 & $\begin{array}{l}389 \\
471 \\
730 \\
758\end{array}$ & $\begin{array}{l}+99.7 /-120.0 \\
\quad+41.3 \\
+22.2 /-26.1 \\
+27.0 /-19.3\end{array}$ \\
\hline
\end{tabular}

frequency at $389^{\circ} \mathrm{C}$ is found, indicating that heat energy is released by the sample. Both enthalpies are given in Table I. Their sum represents the maximum enthalpy change. After accomplishing the phase transformation the measured frequency approaches the undisturbed frequency.

Figure 8 shows the second phase transformation around $471^{\circ} \mathrm{C}$. In contrast to the previous one, it is a pure endothermic process. A positive frequency shift of $\Delta f=+155 \mathrm{~Hz}$ is found that is equal to an enthalpy of $\Delta H=+41.3 \mathrm{~J} / \mathrm{g}$. Figures 9 and 10 present phase transformations (3) and (4), respectively. Their frequency progressions are quite similar to the first, showing again a two-step transformation. Both start with an endothermic process (frequency increase of $\Delta f=+170 \mathrm{~Hz}$ (3) or $\Delta f=+210 \mathrm{~Hz}$ (4), respectively). Afterwards an exothermic process is observed. The related frequency decreases below the undisturbed frequency fits are $\Delta f=-200 \mathrm{~Hz}$ at $730^{\circ} \mathrm{C}$ (3) and $\Delta f=-150 \mathrm{~Hz}$ at $758^{\circ} \mathrm{C}$ (4). The related enthalpies are given in Table I, too.

During cooling no phase transformations are observed. Therefore, phase transformation (4) is irreversible. Such a conclusion cannot be done for phase transformations (1) to (3) since the temperature increases continuously up to transformation (4) during this measurement.

TFC in ambient air. - The results of the TFC in ambient air and the corresponding structural analysis are already published in Ref. 39. Here, they are briefly presented for comparison with new results acquired at low $p_{\mathrm{O}_{2}}$.

LMO exhibits three phase transformations in ambient air at (1) $330^{\circ} \mathrm{C}$, (2) $410^{\circ} \mathrm{C}$ and (3) $600^{\circ} \mathrm{C}$. Figure 11 shows the frequency over the entire temperature range during heating. Again, the positions of the three phase transformations are marked, although not been visible in this scale. Enlarged plots of these areas are published in Ref. 39.

All of these phase transformations start with an area of reduced heat consumption indicating an endothermic behavior. As in case of the measurements carried out in $0.5 \% \mathrm{H}_{2} / \mathrm{Ar}$, this is interpreted as an endothermic process to trigger the related crystallization. Subse-

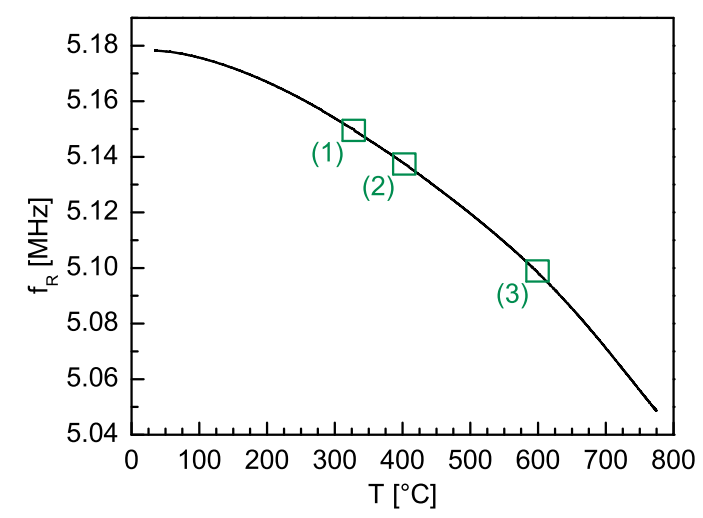

Figure 11. Overview of the TFC diagram for heating LMO in ambient air (RT up to $774^{\circ} \mathrm{C}$ ). The positions of the three phase transformations are indicated by squares. Details are given in Ref. 39. quently, a frequency drop is found indicating heat energy release by the sample. Both enthalpies are given in Table I.

Phase transformation (1) shows a frequency deviation which corresponds to an activation enthalpy (frequency increase by $+280 \mathrm{~Hz}$ ) and a subsequent exothermic process (frequency decrease by $-210 \mathrm{~Hz}$ ). Phase transformation (2) is associated with frequencies of $+105 \mathrm{~Hz}$ (activation) and $-105 \mathrm{~Hz}$ (exothermic enthalpy), respectively. The frequency deviations for phase transformation (3) are bigger, however, resulting in a slightly smaller enthalpy. The apparent discrepancy is caused by the increasing temperature dependence of the resonance frequency with increasing temperature. An activation energy (frequency increase by $+150 \mathrm{~Hz}$ ) followed by an exothermic process (frequency decrease by $-190 \mathrm{~Hz}$ ) is found. ${ }^{39}$

Structural analysis: XRD analysis and Raman spectroscopy.- In order to detect all phase transformations the TFC measurement should be carried out by applying a constant temperature ramp. This avoids falsifications by intermediate cooling steps. Consequently, the structure of films deposited on the LGS resonators can be investigated after accomplishing the TFC measurements, only. Phases occurring at intermediated temperatures are determined using LMO reference films deposited on stainless steel substrates. After annealing above about $700^{\circ} \mathrm{C}$ the phases can be determined on both substrates and are found to be independent of the substrate as shown in Figure 15. This observation confirms the comparability of the films deposited on stainless steel and LGS resonators.

$X R D$ analysis of LMO annealed in a $0.5 \% \mathrm{H}_{2} / \mathrm{Ar}$ atmosphere.- The $\mathrm{XRD}$ analysis of the as-deposited sample shows reflections of the stainless steel substrate, only (see Figure 12). Consequently, the asdeposited LMO film is amorphous. After annealing, a significant LMO reflection at $2 \Theta \approx 18.7^{\circ}$ is found. Based on the accuracy of the XRD analysis, it cannot be decided if the signal is caused by the layered monocline rock salt $\mathrm{Li}_{2} \mathrm{MnO}_{3}\left(\mathrm{~m}-\mathrm{Li}_{2} \mathrm{MnO}_{3}, 18.70^{\circ 51}\right)$ or

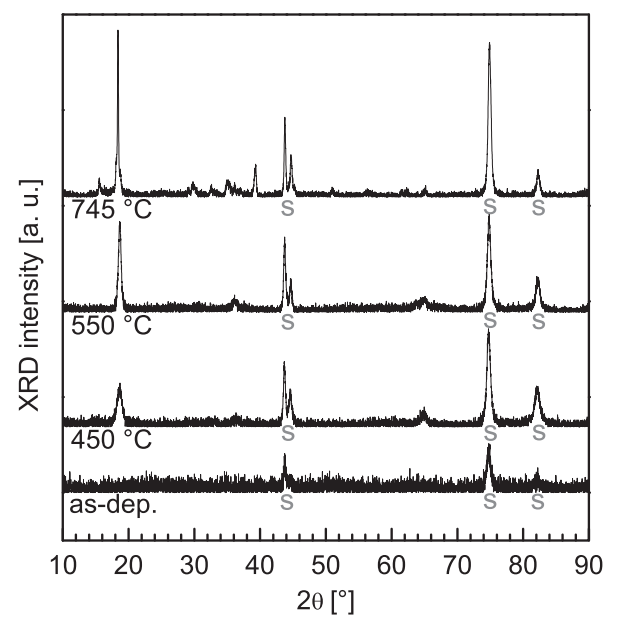

Figure 12. XRD diffraction patterns of LMO deposited on stainless steel substrates before and after annealing in $0.5 \% \mathrm{H}_{2} / \mathrm{Ar}$. The substrate peaks are indicated by "s." 
by the cubic spinel $\mathrm{LiMn}_{2} \mathrm{O}_{4}\left(\mathrm{c}-\mathrm{LiMn}_{2} \mathrm{O}_{4}, 18.61^{\circ 52}\right)$. The samples annealed up to $450^{\circ} \mathrm{C}$ and $550^{\circ} \mathrm{C}$ show two additional weak reflections at $2 \Theta \approx 36.4^{\circ} / 36.1^{\circ}$ and $2 \Theta \approx 65.0^{\circ} / 64.8^{\circ}\left(450^{\circ} \mathrm{C} / 550^{\circ} \mathrm{C}\right)$. These can be attributed to $\mathrm{m}-\mathrm{Li}_{2} \mathrm{MnO}_{3}$ or to c-LiMn $\mathrm{O}_{4} \cdot{ }^{51,52}$ An unambiguous phase assignment based on the XRD diffraction patterns is not possible due to the weaknesses of the peaks.

The X-ray diffraction pattern acquired after annealing at $745^{\circ} \mathrm{C}$ shows a large number of reflections (see Figure 12). In Ref. 49 calculated diffraction patterns of the most common lithium manganese oxides, lithium oxides and manganese oxides are presented. The modeling of the diffraction patterns bases on $\mathrm{Cu}-\mathrm{K}_{\alpha}$ radiation and the structural formulas of the Inorganic Crystal Structure Database (ICSD). For this work, the ICSD cards for orthorhombic $\mathrm{LiMnO}_{2}$ $\left(\mathrm{o}-\mathrm{LiMnO}_{2}\right){ }^{53}$ monocline $\mathrm{LiMnO}_{2}\left(\mathrm{~m}-\mathrm{LiMnO}_{2}\right)^{54}$ and tetragonal $\mathrm{Mn}_{3} \mathrm{O}_{4}\left(\mathrm{t}-\mathrm{Mn}_{3} \mathrm{O}_{4}\right)^{55}$ are primarily considered. On the one hand, most of the measured diffraction peaks clearly match to $t-\mathrm{Mn}_{3} \mathrm{O}_{4}$, $\mathrm{o}-\mathrm{LiMnO}_{2}$ and the stainless steel substrate confirming the occurrence of these phases. On the other hand, several of the peaks show very good agreement with $\mathrm{m}-\mathrm{LiMnO}_{2}$. Especially, three reflections (001), (20-2) and (111) appear. This is remarkable, as these should be the most prominent $\mathrm{m}-\mathrm{LiMnO}_{2}$ reflections according to the calculations in Ref. 49. The measured peak positions and their assignment to reflections are given in Table II.

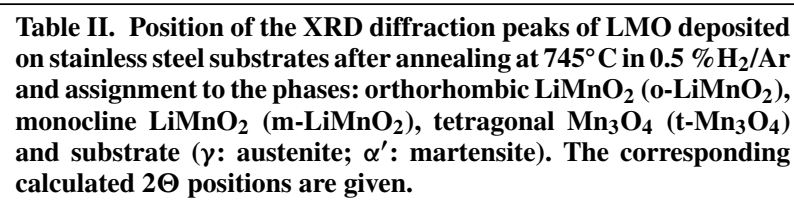

\begin{tabular}{|c|c|c|c|c|c|}
\hline \multicolumn{2}{|c|}{$\begin{array}{l}\text { XRD reflection } \\
\text { positions }\left[{ }^{\circ}\right]\end{array}$} & \multicolumn{4}{|c|}{ Reflections } \\
\hline $\begin{array}{l}\text { this } \\
\text { work }\end{array}$ & Literature $^{49,56}$ & o- $\mathrm{LiMnO}_{2}$ & $\mathrm{~m}-\mathrm{LiMnO}_{2}$ & $\mathrm{t}-\mathrm{Mn}_{3} \mathrm{O}_{4}$ & $\begin{array}{c}\text { Stainless } \\
\text { steel }\end{array}$ \\
\hline 15.5 & 15.39 & (010) & & & \\
\hline 18.3 & $\left\{\begin{array}{l}18.01 \\
18020\end{array}\right.$ & & & (101) & \\
\hline 29.1 & $\begin{array}{l}18.30 \\
28.91\end{array}$ & & (001) & (112) & \\
\hline 29.8 & & & not yet $\mathrm{d}$ & fined & \\
\hline 32.5 & 32.38 & & & (103) & \\
\hline 35.2 & 35.56 & (011) & & & \\
\hline 36.1 & 36.08 & & & (121) & \\
\hline 37.0 & $\left\{\begin{array}{l}36.86 \\
3688\end{array}\right.$ & (120) & & & \\
\hline 38.1 & $\begin{array}{r}36.88 \\
38.09\end{array}$ & & (110) & (004) & \\
\hline & $\{39.21$ & & $(20-2)$ & & \\
\hline 39.3 & $\{39.29$ & (200) & & & \\
\hline 40.8 & 40.80 & (111) & & & \\
\hline 43.8 & 43.73 & & & & $\gamma-(111)$ \\
\hline 1 & 44.41 & & & (220) & \\
\hline 44.7 & 44.67 & & & & $\alpha^{\prime}-(110)$ \\
\hline & $\{45.09$ & (021) & & & \\
\hline 45.2 & $\{45.14$ & & (111) & & \\
\hline 51.0 & 50.83 & & & $(105)$ & \\
\hline 56.2 & 56.02 & & & (033) & \\
\hline 61.5 & $\int 61.32$ & (221) & & & \\
\hline 01.5 & $\{61.55$ & & $(11-3)$ & & \\
\hline 62.5 & 62.90 & (310) & & & \\
\hline & 64.61 & & & (040) & \\
\hline 65.0 & $\{64.97$ & & (202) & & $\alpha^{\prime}-(200)$ \\
\hline $\begin{array}{l}74.9 \\
82.3\end{array}$ & 74.89 & & & & $\begin{array}{c}\gamma-(220) \\
\alpha^{\prime}-(211)\end{array}$ \\
\hline
\end{tabular}

${ }^{1}$ The (220) reflection of $\mathrm{t}-\mathrm{Mn}_{3} \mathrm{O}_{4}$ cannot be observed as it is overlaid of the double peak structure of stainless steel's $\gamma$-(111) and $\alpha^{\prime}-(110)$ reflections.

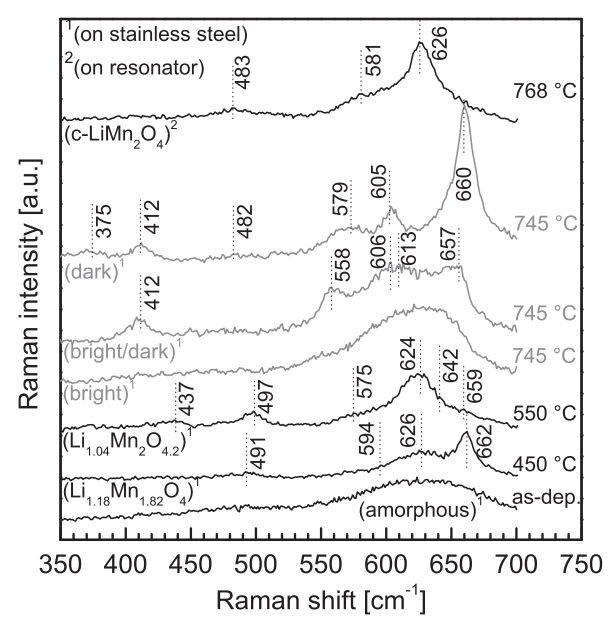

Figure 13. Raman spectra of LMO deposited on different substrates before and after annealing in $0.5 \% \mathrm{H}_{2} / \mathrm{Ar}$.

Raman spectroscopy of LMO annealed in a $0.5 \% \mathrm{H}_{2}$ /Ar atmosphere.Additionally, Raman spectroscopy is performed (see Figure 13). The results support the discussion of the XRD diffraction patterns and enable to evaluate the structures at $450^{\circ} \mathrm{C}$ and $550^{\circ} \mathrm{C}$ in more detail. The as-deposited sample shows no significant Raman bands, proving disordered nearest-neighbor conditions. For the annealed samples a vibrational band is observed at wave numbers of $626 \mathrm{~cm}^{-1}$ and $624 \mathrm{~cm}^{-1}$ at $450^{\circ} \mathrm{C}$ and $550^{\circ} \mathrm{C}$, respectively. These are typical values for the $\mathrm{A}_{1 \mathrm{~g}}$ vibration of a LMO spinel structure. ${ }^{57,58}$ All lithium manganite structures, observed after different annealing steps, display high-wavenumber bands attributed to the $\mathrm{Mn}-\mathrm{O}$ stretching vibrations which dominate the Raman spectra. The low-wavenumber region differs depending on the crystal composition. ${ }^{59}$ If compared to Refs. 58 and 59, the occurrence of stoichiometric compositions is most likely confirmed. To support this statement, additional Raman signals are taken into account. Annealing at $450^{\circ} \mathrm{C}$ results in a spectrum comparable to a stoichiometry of a $\mathrm{Li}$-rich spinel $\left(\mathrm{Li}_{1.18} \mathrm{Mn}_{1.82} \mathrm{O}_{4}{ }^{58}\right)$ while the spectrum for $550^{\circ} \mathrm{C}$ can be assigned to an oxygen-rich spinel (similar to $\mathrm{Li}_{1.04} \mathrm{Mn}_{2} \mathrm{O}_{4.2}{ }^{59}$ ). The spectrum measured on the LMO film deposited on the resonator shows a predominant $A_{1 \mathrm{~g}}$ band at $626 \mathrm{~cm}^{-1}$, too. Additional vibrations at $483 \mathrm{~cm}^{-1}$ and $581 \mathrm{~cm}^{-1}$ indicate the occurrence of a stoichiometric cubic spinel $\mathrm{LiMn}_{2} \mathrm{O}_{4} \cdot{ }^{58}$

Raman spectroscopy of the LMO sample annealed to $745^{\circ} \mathrm{C}$ in a $0.5 \% \mathrm{H}_{2} / \mathrm{Ar}$ atmosphere.- More challenging is the interpretation of the phases after annealing at $745^{\circ} \mathrm{C}$. Here, an optical inspection of the film surface shows regions of different brightness. Dark and bright spots are observed which are embedded in a matrix of iridescent brightness between bright and dark. As the Raman laser spot is much smaller than the spot size of the XRD device, the Raman system enables to focus on the different regions. These Raman spectra are subsequently correlated with the X-ray diffraction pattern which reflects a mixed signal of all three surface regions. Figure 13 shows Raman spectra of each region (bright, mixed bright/dark and dark) which differ significantly.

The Raman spectrum of the bright region exhibits only one broad peak in the range of $500 \mathrm{~cm}^{-1}$ to $700 \mathrm{~cm}^{-1}$. The observation corresponds to a disordered structure. As no vibrational peaks can be determined, statements on the bonding conditions and/or the nearest neighbor behavior cannot be given.

The Raman signal of the dark region shows significant bands at $412 \mathrm{~cm}^{-1}, 579 \mathrm{~cm}^{-1}, 605 \mathrm{~cm}^{-1}$ and $660 \mathrm{~cm}^{-1}$ as well as slight signals at $375 \mathrm{~cm}^{-1}$ and $482 \mathrm{~cm}^{-1}$. The dominating band at $660 \mathrm{~cm}^{-1}$ can be clearly assigned to tetragonal $t-\mathrm{Mn}_{3} \mathrm{O}_{4}$. The broad peaks at $375 \mathrm{~cm}^{-1}$ and $482 \mathrm{~cm}^{-1}$ support the latter interpretation as they are in good agreement with the results on $\mathrm{t}-\mathrm{Mn}_{3} \mathrm{O}_{4}$ presented in Refs. 58 and 60 . The signal at $482 \mathrm{~cm}^{-1}$ can be also assigned to 
m-LiMnO${ }_{2}$, which points to a superimposed signal. The bands at $605 \mathrm{~cm}^{-1}, 579 \mathrm{~cm}^{-1}$ and $412 \mathrm{~cm}^{-1}$ support this conclusion. It must be noted that the latter vibration band is slightly shifted to lower wavenumbers compared to data in Ref. 59. This band shows higher agreement to o- $\mathrm{LiMnO}_{2}$ than to the monocline structure. The spectra of these two structures are very similar since they are only slightly different phases with the same stoichiometry. Further, o- $\mathrm{LiMnO}_{2}$ shows vibrational bands at $411 \mathrm{~cm}^{-1}, 428 \mathrm{~cm}^{-1}, 557 \mathrm{~cm}^{-1}, 613 \mathrm{~cm}^{-1}$ and $655 \mathrm{~cm}^{-1}$ as well as a less prominent at $482 \mathrm{~cm}^{-1}$. ${ }^{61}$ The latter corresponds to the measured signal at the same wavenumber while the former corresponds very well to the measured vibration at $412 \mathrm{~cm}^{-1}$. The other four reflections, belonging to o- $\mathrm{LiMnO}_{2}$, are not directly visible in the measurement data. A more thorough inspection of the measured vibrational bands at $412 \mathrm{~cm}^{-1}, 579 \mathrm{~cm}^{-1}, 605 \mathrm{~cm}^{-1}$ and $660 \mathrm{~cm}^{-1}$ shows that all of them exhibit asymmetric flanks or broadened profiles. As stated before, these vibrations can be attributed to $\mathrm{t}-\mathrm{Mn}_{3} \mathrm{O}_{4}$ and to $\mathrm{m}-\mathrm{LiMnO}_{2}$, on the one hand. On the other hand, the asymmetries indicate additional signals hiding in the dominating vibrations. These assumed signal positions are in close accordance to the vibrational bands of o- $\mathrm{LiMnO}_{2}$.

The spectrum taken on the mixed bright/dark matrix region reflects contributions of the homogeneous regions: Like in the bright case, the broad peak is prominent. Additionally, some slight signals are visible which can be assigned to $\mathrm{LiMnO}_{2}$. Here, the agreement with the orthorhombic structure is very good for all bands except for that at $606 \mathrm{~cm}^{-1}$ which fits to $\mathrm{m}-\mathrm{LiMnO}_{2}$. Based on the three Raman spectra, a structural composition of $\mathrm{t}-\mathrm{Mn}_{3} \mathrm{O}_{4}$ and $\mathrm{LiMnO}_{2}$ is assumed. For the latter, it cannot be concluded, if the crystallographic structure is monocline or orthorhombic.

Summary of the structural investigations on LMO annealed in $0.5 \% \mathrm{H}_{2} / \mathrm{Ar}$ atmosphere.-Combining the Raman and X-ray results, it can be concluded that the sample annealed at $745^{\circ} \mathrm{C}$ consists of $\mathrm{t}-\mathrm{Mn}_{3} \mathrm{O}_{4}$ and polymorphs of $\mathrm{LiMnO}_{2}$. The latter is a mixture of orthorhombic and monocline structures whereby o- $\mathrm{LiMnO}_{2}$ seems to dominate. The coexistence of both phases with a dominant contribution of the orthorhombic phase is a known phenomenon which is caused by stacking faults in o- $\mathrm{LiMnO}_{2}$. The insertion of the fault corresponds to the occurrence of a monoclinic cell between two blocks of orthorhombic symmetry. ${ }^{62}$

This given explanation is in agreement with Ref. 63. Here, LMO powder samples are annealed at different oxygen partial pressures $\left(p_{O_{2}}\right)$. At high $p_{O_{2}}$ a tendency of coexistence of the phases $\mathrm{Li}_{2} \mathrm{MnO}_{3}$ and $\mathrm{LiMn}_{2} \mathrm{O}_{4}$ is observed while at low $p_{\mathrm{O}_{2}} \mathrm{o}-\mathrm{LiMnO}_{2}$ is the most stable LMO phase. At low $p_{O_{2}}$, considerable amounts of $\mathrm{t}-\mathrm{Mn}_{3} \mathrm{O}_{4}$ are formed. This observation can be explained by different valence states of the $\mathrm{Mn}$ ions in the compounds. $\mathrm{Li}_{2} \mathrm{MnO}_{3}$ consists of $\mathrm{Mn}^{4+}$ ions and

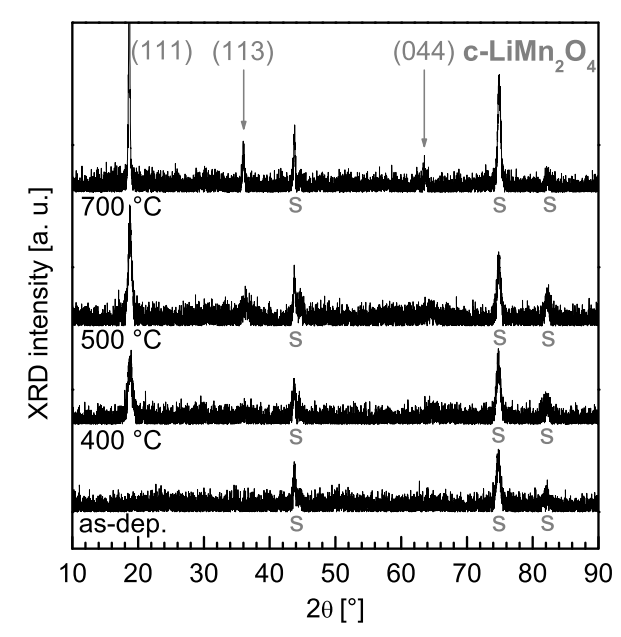

Figure 14. XRD diffraction patterns of LMO deposited on stainless steel substrates annealed in ambient air. The substrate peaks are indicated by "s".

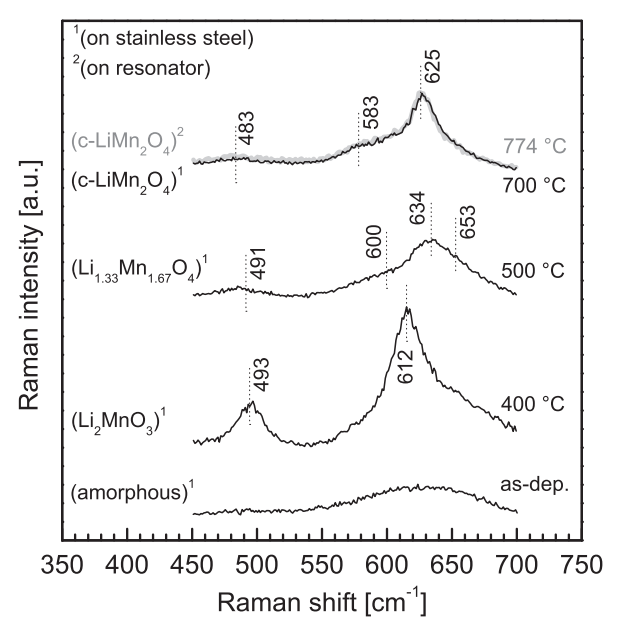

Figure 15. Raman spectra of LMO deposited on different substrates before and after annealing in ambient air. ${ }^{39}$

$\mathrm{LiMn}_{2} \mathrm{O}_{4}$ exhibits a ratio of $\mathrm{Mn}^{4+}: \mathrm{Mn}^{3+}=1$. Consequently, at high $p_{\mathrm{O}_{2}}$ tetravalent manganese is preferred. Low $p_{\mathrm{O}_{2}}$ results in a tendency to trivalent manganese as found in $\mathrm{LiMnO}_{2}$ and preferred in $\mathrm{Mn}_{3} \mathrm{O}_{4}$.

XRD analysis of LMO annealed in ambient air.- The XRD analysis of the as-deposited sample shows only the reflections of the substrate (see Figure 14). After annealing, a significant LMO reflection at $2 \Theta \approx 18.7^{\circ}$ is found. As in $0.5 \% \mathrm{H}_{2} / \mathrm{Ar}$, it cannot be decided, if the signal belongs to the layered monocline rock salt $\mathrm{Li}_{2} \mathrm{MnO}_{3}\left(18.70^{\circ 51}\right)$ or to the cubic spinel $\mathrm{LiMn}_{2} \mathrm{O}_{4}\left(18.61^{\circ 52}\right)$. The pattern show additional reflections at higher angles, but they are too weak for a reliable assignment. After annealing at $700^{\circ} \mathrm{C}$, two of these peaks are more pronounced and can be attributed to the cubic spinel $\mathrm{LiMn}_{2} \mathrm{O}_{4}{ }^{58}$ Consequently, only after annealing at $700^{\circ} \mathrm{C}$ the occurrence of the latter phase is confirmed. Further peaks belonging to LMO are absent.

Raman spectroscopy of LMO annealed in ambient air-- Figure 15 shows the Raman spectra of the LMO samples on stainless steel substrates as well as of the LMO coated langasite resonator after the TFC measurement. After annealing at $400^{\circ} \mathrm{C}$, the Raman spectrum reflects the layered monocline rock salt $\mathrm{Li}_{2} \mathrm{MnO}_{3}{ }^{64}$ while at $500^{\circ} \mathrm{C}$ and $700^{\circ} \mathrm{C}$ spinels are found. The $\mathrm{A}_{1 \mathrm{~g}}$ vibration at $634 \mathrm{~cm}^{-1}$ in the sample annealed at $500^{\circ} \mathrm{C}$ belongs to the $\mathrm{Li}$-rich spinel phase $\mathrm{Li}_{1.33} \mathrm{Mn}_{1.67} \mathrm{O}_{4}$. Moreover, this interpretation is consistent with the vibration positions at about $490 \mathrm{~cm}^{-1}$ and $590 \mathrm{~cm}^{-1} \cdot{ }^{58}$ At $700^{\circ} \mathrm{C}$, the $A_{1 \mathrm{~g}}$ vibration is shifted to $625 \mathrm{~cm}^{-1}$ which corresponds the stoichiometric cubic spinel $\mathrm{LiMn}_{2} \mathrm{O}_{4}$. Moreover, the Raman shift to lower wavenumbers with a decreasing Li:Mn ratio is in accordance with Refs. 58 and 65. In summary, the temperature increase goes along with a clearly visible peak shift, especially for the $A_{1 g}$ vibration in the range from $620 \mathrm{~cm}^{-1}$ to $640 \mathrm{~cm}^{-1}$.

As described before, the temporary formation of the $\mathrm{Li}_{2} \mathrm{MnO}_{3}$ is common for annealing at high $p_{O_{2}}$, e.g. ambient air, and, thereby, in accordance with Ref. 63. A more thorough discussion on the structural change of LMO annealed in ambient air is given in Ref. 39.

\section{Conclusions and Outlook}

The successful operation of the newly developed TFC system is demonstrated. The technique is suited to detect and evaluate temperatures and enthalpies of phase transformations in battery materials. The TFC system as presented in this work circumvents the disadvantages of existing calorimetric techniques for thin films. In contrast to common thin-film systems, the presented TFC is applicable up to high-temperatures of at least $1000^{\circ} \mathrm{C}$. A significant advantage is the operation of a piezoelectric resonator as a precise temperature sensor. 


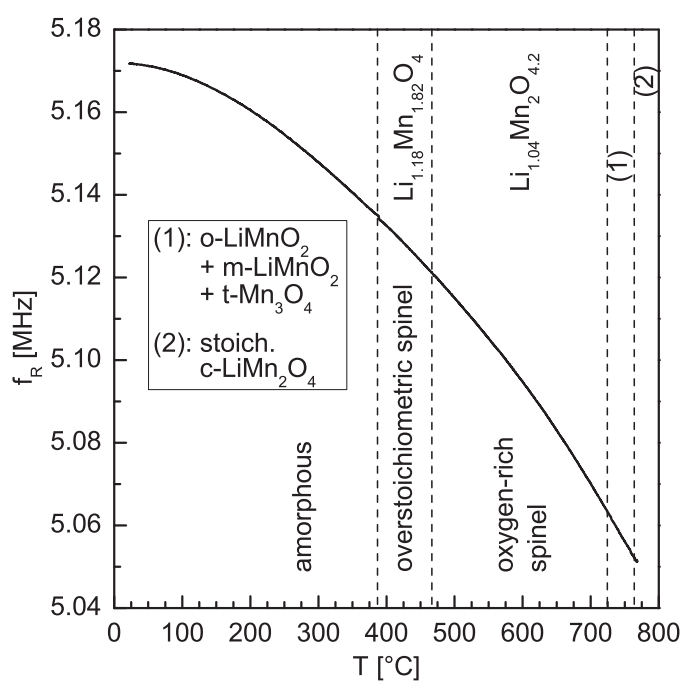

Figure 16. Phases of the LMO thin film. The structural changes and resonance frequency are given as function of temperature. The measurements are carried out in $0.5 \% \mathrm{H}_{2} / \mathrm{Ar}$.

Further, a data evaluation approach is presented to determine temperatures and enthalpies of phase transformations. Additional X-ray diffraction and Raman spectroscopy enables to identify the related crystallographic structures.

The TFC measurements on LMO uncover a significant change in the thin-film behavior in dependence of the atmosphere. In ambient air three phase transformations are observed while in $0.5 \% \mathrm{H}_{2} / \mathrm{Ar}$ even four are detected. The onset of the crystallization of the amorphous layers depends on the atmosphere and is found at lower temperatures in ambient air. In other words, the amorphous phase is more stable at low $p_{\mathrm{O}_{2}}$ than in ambient air. In $0.5 \% \mathrm{H}_{2} / \mathrm{Ar}$ the LMO thin film crystallizes initially in a spinel structure. Here, at first two off-stoichiometric phases are formed (first a Li-rich spinel, subsequently an oxygen-rich spinel). They are followed by a small temperature area consisting of three interfering phases (polymorphs of $\mathrm{LiMnO}_{2}$ and $\mathrm{t}-\mathrm{Mn}_{3} \mathrm{O}_{4}$ ). Finally, the film crystallizes in the stoichiometric cubic spinel $\mathrm{LiMn}_{2} \mathrm{O}_{4}$.

The intermediate region with three different phases is detected in the Ar based atmosphere, only. In ambient air a direct phase transformation from Li-rich spinel to the stoichiometric cubic spinel is

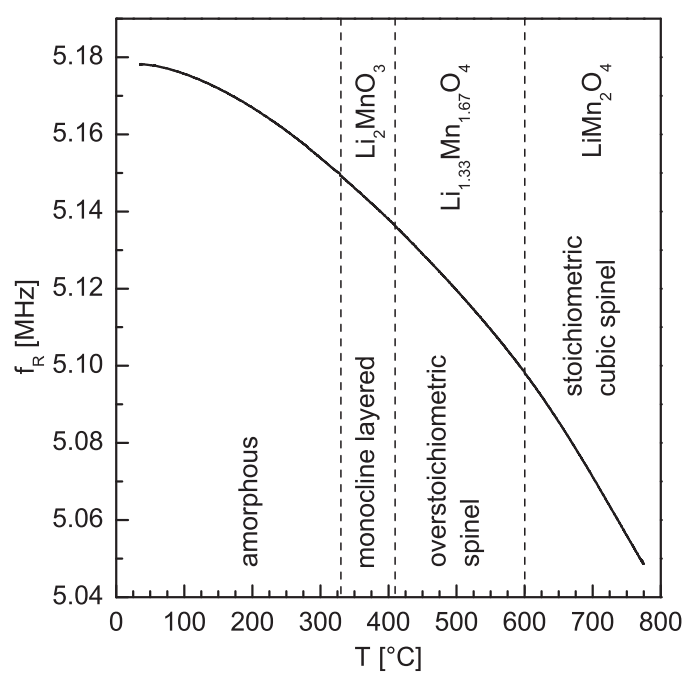

Figure 17. Phases of the LMO thin film. The structural changes and resonance frequency are given as function of temperature. The measurements are carried out in ambient air. observed. Moreover, it is remarkable that the crystallization process in ambient air starts with a non-spinel phase, although the amorphous phase exhibits a near-stoichiometric spinel composition of 1:2:4. The first phase that appears at high $p_{O_{2}}$ is $\mathrm{Li}_{2} \mathrm{MnO}_{3}$. The process is probably supported by the availability of oxygen in the measurement atmosphere. Figures 16 and 17 show the structural changes and resonance frequency over temperature. Further, the associated phase regions are given.

\section{Acknowledgments}

The authors gratefully acknowledge the financial support of the German Research Foundation (Deutsche Forschungsgemeinschaft, DFG) within the DFG priority program 1473 "WeNDeLIB - Werkstoffe mit Neuem Design für Lithium-Ionen-Batterien".

In addition, the authors thank the Energie-Forschungszentrum Niedersachsen (Energy Research Centre of Niedersachsen, EFZN) for supporting this work.

\section{References}

1. A. Patil, V. Patil, D. W. Shin, J.-W. Choi, D.-S. Paik, and S.-J. Yoon, Materials Research Bulletin, 43, 1913 (2008).

2. D. Larcher, S. Beattie, M. Morcrette, K. Edström, J.-C. Jumasc, and J.-M. Tarascon, Journal of Materials Chemistry, 17, 3759 (2007)

3. R. Sousa, J. F. Ribeiro, J. A. Sousa, L. M. Goncalves, and J. H. Correia, 2013 IEEE 3rd Portuguese Meeting in Bioengineering (ENBENG), 1 (2013).

4. M. S. Whittingham, Chemical Reviews, 104, 4271 (2004).

5. V. Palomares and T. Rojo, in Lithium Ion Batteries - New Developments, I Belharouak, Editor, p. 4/7/8, InTech, Rijeka (2012).

6. M. S. Whittingham, Y. Song, S. Lutta, P. Y. Zavalij, and N. A. Chernova, Journal of Materials Chemistry, 15, 3362 (2005).

7. A. D. Robertson and P. G. Bruce, Chemistry of Materials, 15, 1984 (2003).

8. T. Ohzuku and Y. Makimura, Chemistry Letters, 30, 744 (2001).

9. D. Albrecht, H. Wulfmeier, S. Ivanov, A. Bund, and H. Fritze, Materials Research Society Symposium Proceedings, 1496(J) (2013).

10. D. Albrecht, H. Wulfmeier, S. Ivanov, A. Bund, and H. Fritze, Journal of Applied Electrochemistry, 43, 559 (2013).

11. M. Ohring, Materials Science of Thin Films - Deposition and Structure, 2nd ed. p. 2, Academic Press, San Diego (2002)

12. L. Wojtczak, Physica Status Solidi b, 23, K163 (1967).

13. S. Franssila, Introduction to Microfabrication, 2nd ed., p. 58, John Wiley \& Sons Ltd., Chichester (2010).

14. W. Fang and C.-Y. Lo, Sensors and Actuators, 84, 310 (2000).

15. A. W. van Heerwaden, Thermochimica Acta, 432, 192 (2005).

16. S. L. Lai, G. Ramanath, L. H. Allen, and P. Infante, Applied Physical Letters, 70, 43 (1997).

17. M. Zhang, M. Y. Efremov, F. Schiettekatte, E. A. Olson, A. T. Kwan, S. L. Lai, T. Wisleder, J. E. Greene, and L. H. Allen, Physical Review B, 62, 10548 (2000)

18. M. Y. Efremov, E. A. Olson, M. Zhang, S. L. Lai, F. Schiettekatte, Z. S. Zhang, and L. H. Allen, Thermochimica Acta, 412, 13 (2003).

19. H. Wulfmeier, D. Albrecht, S. Ivanov, A. Bund, and H. Fritze, Proceedings 11 Dresdner Sensor-Symposium, 34 (2013)

20. D. W. Denlinger, E. N. Abarra, K. Allen, P. W. Rooney, M. T. Messer, S. K. Watson, and F. Hellman, Review of Scientific Instruments, 65, 946 (1994).

21. J. Lerchner, A. Wolf, and G. Wolf, Journal of Thermal Analysis and Calorimetry, 57, 241 (1999).

22. G. W. H. Höhne and W. Winter, Thermochimica Acta, 432, 169 (2005).

23. J. Lerchner, A. Wolf, G. Wolf, V. Baier, E. Kessler, M. Nietzsch, and M. Krügel, Thermochimica Acta, 445, 144 (2006).

24. A. A. Minakov, S. A. Adamovsky, and C. Schick, Thermochimica Acta, 432, 177 (2005).

25. T. Wagner, M. Munzar, M. Krbal, and S. O. Kasap, Thermochimica Acta, 432, 241 (2005).

26. B. E. Handy, S. B. Sharma, B. E. Spiewak, and J. A. Dumesic, Measurement Science and Technology, 4, 1350 (1993).

27. C. Michaelsen, K. Barmak, and T. P. Weihs, Journal of Physics D: Applied Physics, 30, 3167 (1997)

28. F. Spaepen and C. V. Thompson, Applied Surface Science, 38, 1 (1989).

29. C. E. Porter and F. D. Blum, Macromolecules, 33, 7016 (2000).

30. J. Lerchner, R. Kirchner, J. Seidel, D. Wählisch, and G. Wolf, Thermochimica Acta, 415, 27 (2004).

31. A. L. Smith and H. M. Shirazi, Thermochimica Acta, 432, 202 (2005).

32. A. L. Smith, S. R. Mulligan, J. Tian, H. M. Shirazi, and J. Riggs, Proceedings of the 2003 IEEE International Frequency Control Symposium and PDA Exhibition Jointly with the 17th European Frequency and Time Forum, 1062 (2003).

33. N. Miura, H. Minamoto, G. Sakai, and N. Yamazoe, Sensors and Actuators B: Chemical, 5, 211 (1991). 
34. R. W. Cernosek, J. R. Bigbie, M. T. Anderson, J. H. Small, and P. S. Sawyer, SolidState Sensor and Actuator Workshop, Hilton Head Island, South Carolina, 8. 11.6.1998 (1998).

35. H. Fritze, Measurement Science and Technology, 22, 012002 (2011).

36. J. Hornsteiner, E. Born, and E. Riha, physica status solidi (a), 163, R3 (1997).

37. H. Fritze, H. L. Tuller, G. Borchardt, and T. Fukuda, Materials Research Society Symposium Proceedings, 604, 65 (2000).

38. M. Schulz and H. Fritze, Journal of Renewable Energy, 33, 336 (2008).

39. H. Wulfmeier, D. Albrecht, S. Ivanov, J. Fischer, S. Ulrich, A. Bund, and H. Fritze, Journal of Materials Science, 48, 6585 (2013).

40. H. Wulfmeier, D. Albrecht, S. Ivanov, J. Fischer, R. Grieseler, P. Schaaf, S. Ulrich, A. Bund, and H. Fritze, Materials Research Society Symposium Proceedings, 1496(J) (2013).

41. T. Schneider, D. Richter, S. Dörner, H. Fritze, and P. Hauptmann, Sensors and Actuators B, 111-112, 187 (2005).

42. P. J. van Ekeren, C. M. Holl, and A. J. Witteveen, Journal of ThermaI Analysis, 49, 1105 (1997).

43. J. Sauerwald, D. Richter, E. Ansorge, B. Schmidt, and H. Fritze, Physica Status Solidi a, 208, 390 (2011).

44. H. Kong, J. Wang, H. Zhang, X. Yin, S. Zhang, Y. Liu, X. Cheng, L. Gao, X. Hu, and M. Jiang, Journal of Crystal Growth, 254, 360 (2003).

45. A. F. Lopeandía, L. 1. Cerdó, M. T. Clavaguera-Mora, L. R. Arana, K. F. Jensen, F. J. Muñoz, and J. Rodríguez-Viejo, Review of Scientific Instruments, 76, 065104 (2005).

46. S. L. Lai, G. Ramanath, L. H. Allen, and P. Infante, Applied Physics Letters, 70, 43 (1996).
47. W. F. Hemminger and H. K. Cammenga, Methoden der Thermischen Analyse, 1st ed., p. 128, Springer-Verlag, Berlin (1989).

48. J. Fischer, D. Music, T. Bergfeldt, C. Ziebert, S. Ulrich, and H. J. Seifert, Thin Solid Films, 572, 208 (2014)

49. J. Fischer, dissertation, Karlsruhe Institute of Technology (2014).

50. G. Sauerbrey, Zeitschrift für Physik A, 155, 206 (1959).

51. JCPDS database, pdf card number 00-027-1252.

52. JCPDS database, pdf card number 00-035-0782.

53. ICSD database, pdf card number 81051 .

54. ICSD database, pdf card number 82993 .

55. ICSD database, pdf card number 68174.

56. N. Arikan, master thesis, Karlsruhe Institute of Technology (2013).

57. C. M. Julien, Materials Science and Engineering, R40, 47 (2003).

58. C. M. Julien and M. Massot, Materials Science and Engineering, B97, 217 (2003).

59. C. M. Julien, M. Massot, R. Baddour-Hadjean, S. Franger, S. Bach, and J. P. Pereira-Ramos, Solid State Ionics, 159, 345 (2003).

60. T. Gao, H. Fjellvåg, and P. Norby, Analytica Chimica Acta, 648, 235 (2009)

61. L. Z. Zhao, Y. W. Chen, and G. R. Wang, Solid State Ionics, 181, 1399 (2010).

62. L. Croguennec, P. Deniard, R. Brec, and A. Lecerf, Journal of Materials Chemistry, 7, 511 (1997).

63. Y.-I. Jang and Y.-M. Chiang, Solid State Ionics, 130, 53 (2000).

64. C. M. Julien and M. Massot, Materials Science and Engineering, B100, 69 (2003).

65. C. M. Julien and M. A. Camacho-Lopez, Materials Science and Engineering, B108, 179 (2004). 